\title{
Effects of Elimination of Activity on Contractile and Histochemical Properties of Rat Soleus Muscle ${ }^{1}$
}

\author{
SIDNEY A. SPECTOR ${ }^{2}$ \\ Department of Kinesiology, University of California, Los Angeles, California 90024
}

\begin{abstract}
Morphological, contractile, and histochemical properties of rat soleus muscle were studied after 2 or 4 weeks of complete elimination of neuromuscular activity. Inactivity was induced by chronic perfusion of tetrodotoxin (TTX) to the sciatic nerve. Significant reductions in muscle mass and fiber size were found after 2 or 4 weeks of disuse. Correspondingly, the percentage of dark-staining alkaline myosin ATPase fibers was increased from about $20 \%$ to $40 \%$ after 4 weeks of treatment. The capacity of soleus to generate tension when stimulated through the nerve was significantly impaired at frequencies greater than $20 \mathrm{~Hz}$. Nevertheless, when the curarized muscle was stimulated directly, tension developed at frequencies above $20 \mathrm{~Hz}$ relative to peak tension was similar to control values. Absolute tetanic tension was significantly reduced after 2 or 4 weeks of treatment. These reductions could be only partly explained by muscle atrophy, resulting in specific tensions or approximately $55 \%$ of control after 2 or 4 weeks of treatment. Measures of the time course of the isometric twitch were found not to be reliable indicators of the contractile speed in TTX-treated soleus. Significant increases in the rate of tetanic tension development, expressed relative to peak tension, and the velocity of unloaded shortening, were seen after 4 weeks of disuse. These results reveal the extent to which virtually complete neuromuscular inactivity leads to chronic deficits in neuromuscular transmission and changes in both the net amount and quality of contractile proteins of rat soleus muscle.
\end{abstract}

Atrophy and changes in the physiological characteristics of skeletal muscle occur with joint immobilization, tenotomy, denervation, spiral cord transeclion, and hindlimb suspension (Eccles, 1944; Karpati and Engel, 1968; Maier et al., 1976; Johnson et al., 1982; Musacchia et al., 1983). These treatments commonly have been grouped as models of disuse, that is, conditions which reduce muscular activity. However, each of these models differs from one another with respect to (1) the amount and quality of remaining neuromuscular activity (Vrbova, 1963; Fishbach and Robbins, 1969;

Received November 16, 1984; Revised February 27, 1985; Accepted March 13, 1985

${ }^{1}$ This work was supported by National Institutes of Health grant NS16333 awarded to $V$. Reggie Edgerton and was undertaken, in part, at the Jerry Lewis Neuromuscular Research Center. I thank Drs. V. Reggie Edgerton, Earl Homsher, and Michael S. Letinsky for critically reviewing this manuscript. The technical contributions of Nicholas V. Ricchiuti, Cesar Blanco, and Mary C. Carter are appreciated.

${ }^{2}$ Present address: Laboratory of Neural Control, National Institutes of Health, NINCDS, Building 36, Room 5A29, Bethesda, MD 20205.
Fournier el al., 1983; Aliarno et al., 1984), (2) the maintained availability to the muscle of putative trophic factors supplied by the motor nerve (Gutmann, 1976; McArdle, 1983), and (3) the influence of passive or active tension development on the treated muscle (Goldspink, 1977, 1978; Spector et al., 1982). Therefore, effects attributed to muscle disuse may, in fact, stem from the reduction of neuromuscular activity associated with the influence of these other physiological stimuli.

Prolonged and complete neuromuscular disuse has been at tempted with neurotoxins (Ochs, 1982) or by spinal cord transection combined with dorsal root rhizotomy (Tower, 1937). Although spinal cord-isolated muscles are atrophic and exhibit alterations in contractile and biochemical properties, even this treatment may not eliminate all neuromuscular activity and, in some cases, produces ventral root degeneration (Tower, 1937; Eccles, 1944; Eldridge et al., 1981) Alternatively, neurotoxins such as botulinum toxin, bungarotoxin, batrachotoxin, and tetrodotoxin (TTX) block nerve impulse propagation or synaptic transmission. However, only TTX applied to peripheral nerve may eliminate action potential propagation without denervation, while permitting normal, fast axoplasmic flow and spontaneous release of acetylcholine at the neuromuscular junction (Pestronk et al., 1976; Lavoie et al., 1977; Czeh et al., 1978; Bray et al., 1979; Betz et al., 1980). Therefore, of the neurotoxins, TTX treatment most effectively permits the study of complete neuromuscular inactivity independent of other physiological influences on changes in the physiological properties of muscle.

Whereas muscles chronically inactivated with nerve-applied TTX are atrophic and exhibit changes in their electrophysiological properties (Pestronk et al., 1976; Lavoie et al., 1977; Bray et al., 1979), the effects on the force output or contractile kinetics of these muscles have not been studied in detail (Czeh et al., 1978). Furthermore, characterization of alterations in the size of muscle fibers and population distributions of fiber types has not been undertaken. The present study, therefore, implemented chronic ITX treatment to investigate the effects of complete and prolonged disuse of 2 or 4 weeks on the contractile and histochemical characteristics of the slow twitch soleus muscle of the rat. The results demonstrate extensive fiber atrophy and chronic deficits in neuromuscular transmission and contractile function due to neuromuscular inactivity Preliminary results of a portion of this study were reported previously (Spector and Edgerton, 1984).

\section{Materials and Methods}

\section{Preparation}

Adult female Sprague-Dawley rats (Rodenetrics, Chatsworth, CA), weighing 170 to $190 \mathrm{gm}$, were used in all experiments. Surgery was performed in an aseptic environment on animals anesthetized with an intraperitoneal injection of sodium pentobarbital (Nembutal; $30 \mathrm{mg} / \mathrm{kg}$ ). Pairs of rats were housed in cages with sawdust-covered floors and were fed water and rat chow ad libitum. For terminal experiments, rats werc similarly ancsthetized until after the completion of all mechanical measurements on soleus muscles. 


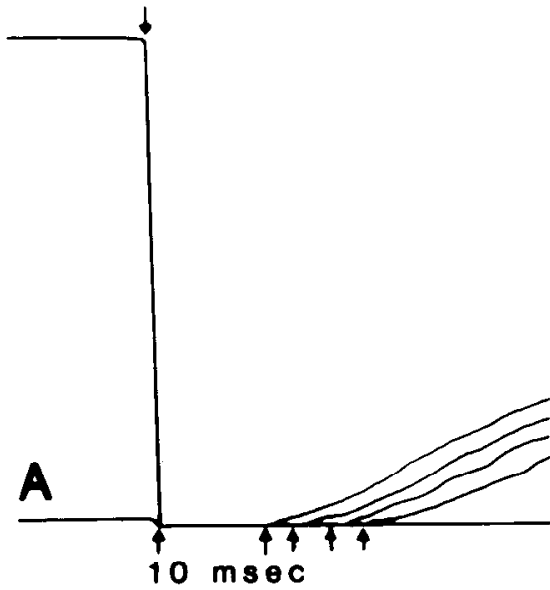

400

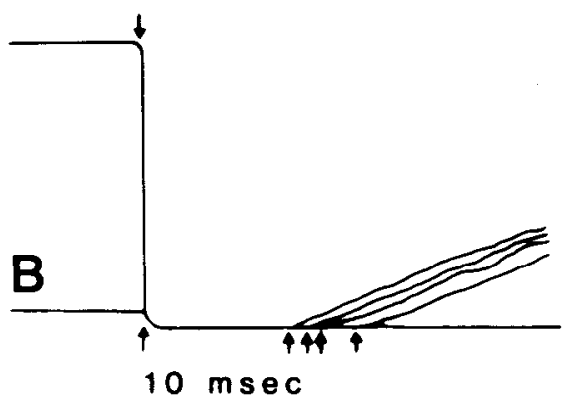

200
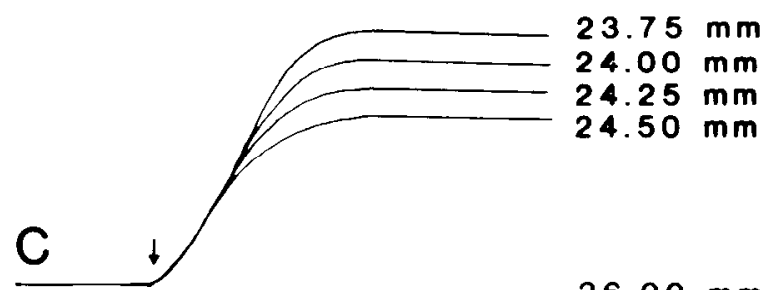

$2 \mathrm{msec}$

Figure 1. Examples of hand tracings of tension records of a 2-week treated sham $(A)$ and contralateral TTX $(B)$ soleus muscle used for determination of

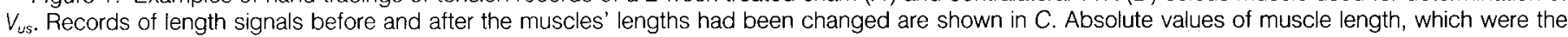

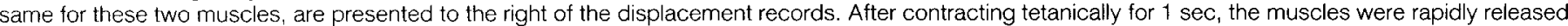

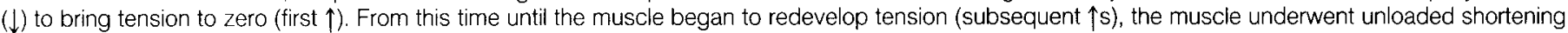

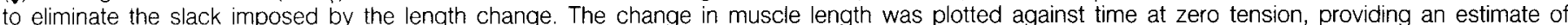

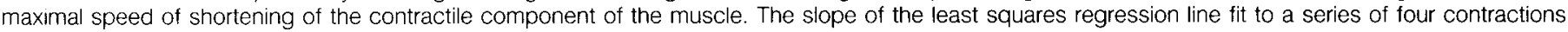

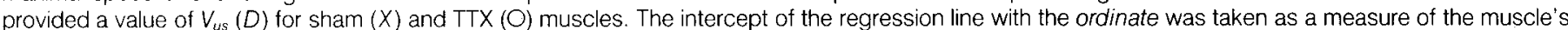
series elasticity (Edman, 1979).

\section{Chronic TTX disuse}

Sciatic nerve action potentials were blocked by chronic perfusion of TTX as described by Betz et al. (1980). TTX (Sigma Chemical Co., St. Louis, MO) was dissolved in isotonic bicarbonate Ringer's solution $(\mathrm{pH} 7.2 ; 500 \mu \mathrm{g} / \mathrm{ml})$ and injected into an osmotic mini-pump (model 2002. Alza Corp., Palo Alto CA) which held a volume of $225 \mu \mathrm{l}$. TTX was perfused continuously at a rate of $0.5 \mu \mathrm{l} / \mathrm{hr}$ for 14 days. In animals paralyzed for 4 weeks, the initial pump was romoved and roplaccd after 2 wocks with a freshly supplied pump secured to the original catheter and nerve cuff (described below)

The sciatic nerve was exposed by longitudinal incision and retraction of hamstring musculature along the posterolatcral aspect of the thigh. To limit application of TTX to a small portion of the sciatic nerve, Silastic tubing (inner diameter, $0.5 \mathrm{~mm}$; outer diameter, $0.9 \mathrm{~mm}$ ) was led from the mini-pump to a longitudinally slit cuff ( $5 \mathrm{~mm}$ long) made of Silastic tubing (inner diameter, $1.5 \mathrm{~mm}$; outer diameter, $2.4 \mathrm{~mm}$ ). The cuff was secured loosely around the sciatic nerve in the midregion of the thigh. The osmotic pump was placed subcutaneously along the lumbosacral vertebral column.

\section{Daily care}

Daily monitoring of the toe extension reflex, normally observed when the rat's hindlimbs are lifted off the ground by the tail, was used as an indication of paralysis of musculature innervated distal to the nerve block. Further evidence of total inactivity was made by in vivo assessment of electromyographic activity of TTX-treated and control muscles. Periodically (two to four times/treatment), fine wire electrodes were implanted bilaterally in lumbrical musculature of approximately half of the rats. Clectrical signals were amplified and filtered, and the resulting interference patterns were monitored using an oscilloscope and recorded on FM tape. Activity patterns were recorded during standing, walking, tail pinching, and elicitation of the toe extension reflex.

In those animals in which the continued absence of the toe extension reflex and electromyographic activity were verified, the ability of the sciatic nerve to conduct action potentials when stimulated above or below the nerve cuff was determined in situ at the end of treatment. Twitch tension was recorded in response to stimulation of the sciatic nerve distal to the TTX block with a bipolar platinum wire electrode connected to a stimulator. The voltage amplitude and pulse width were adjusted until a maximal twitch response was evoked. Muscles which did not contract after sciatic nerve stimulation proximal to the cuff with up to 50 times this voltage were kept for further analysis. 
TABLE I

Morphology of rat soleus muscle after 2 or 4 weeks of $T X X$ inactivation

\begin{tabular}{|c|c|c|c|c|c|c|}
\hline \multirow[b]{3}{*}{ Muscle weightl (rng) } & \multicolumn{3}{|c|}{ Two Weeks } & \multicolumn{3}{|c|}{ Four Weeks } \\
\hline & $\begin{array}{l}\text { Control } \\
(4)^{2}\end{array}$ & $\begin{array}{l}\text { Sham } \\
(8)\end{array}$ & $\begin{array}{c}T T X \\
(8)\end{array}$ & $\begin{array}{l}\text { Control } \\
\text { (5) }\end{array}$ & $\begin{array}{c}\text { Sham } \\
\text { (4) }\end{array}$ & $\begin{array}{l}\text { TTX } \\
(4)\end{array}$ \\
\hline & $96.1 \pm 3.7^{b}$ & $93.4 \pm 2.9$ & $55.8 \pm 3.6^{c}$ & $108.1 \pm 3.5$ & $112.0 \pm 5.0$ & $50.8 \pm 1.8^{\circ}$ \\
\hline Muscle length (mm) & $24.3 \pm 0.5$ & $24.5 \pm 0.5$ & $25.2 \pm 0.3$ & $27.1 \pm \quad 0.4$ & $26.6 \pm 0.4$ & $26.2 \pm 0.3$ \\
\hline $\begin{array}{l}\text { Whole muscle cross- } \\
\qquad \begin{array}{c}\text { sectional area } \\
\left(\times 10^{-2} \mathrm{~cm}^{2}\right)\end{array}\end{array}$ & $7.37 \pm 0.36$ & $7.08 \pm 0.21$ & $4.17 \pm 0.27^{\circ}$ & $7.41 \pm \quad 0.30$ & $7.84 \pm 0.40$ & $3.59 \pm 0.14^{c}$ \\
\hline \multicolumn{7}{|l|}{$\begin{array}{c}\text { Fiber cross-sectional } \\
\text { area }\left(\mu \mathrm{m}^{2}\right)\end{array}$} \\
\hline Mean & $2077 \pm 35$ & $2042 \pm 27$ & $1090 \pm 15^{c}$ & $2716 \pm 80$ & $2451 \pm 48$ & $680 \pm 14^{c}$ \\
\hline SO fibers & $2236 \pm 37$ & $2231 \pm 29$ & $1196 \pm 17^{\circ}$ & $2936 \pm 75$ & $2527 \pm 53$ & $781 \pm 20^{\circ}$ \\
\hline FOG tibers & $1404 \pm 38$ & $1354 \pm 33$ & $782 \pm 20^{\circ}$ & $2090 \pm 412$ & $1780 \pm 85$ & $567 \pm 14^{c}$ \\
\hline
\end{tabular}

${ }^{a}$ Numbers in parentheses, sample size.

${ }^{b}$ Values are means \pm SEM.

${ }^{c}$ Significant difference between TTX and sham or control.

${ }^{\circ}$ Whole muscle cross-sectional area (Close, 1972) was calculated by dividing muscle volume (muscle weight/density) by the muscle's mean fiber length $(0.51 \mathrm{~mm}$ of muscle length; taken from Spector et al., 1982, for normal soleus). This parameter estimates the physiological cross-sectional area of muscle which may contribute to force production, correcting for that component of muscle mass which lies in series (1.e., muscle tiber length).

\section{In vitro contractile analysis}

Incubation of muscle. After in situ analysis, the soleus muscle was excised and its tendons tied with nylon suture (4.0) to small stainless steel hooks attached to a force transducer and ergometer. The muscle was immersed and equilibrated in an aerated $\left(95 \% \mathrm{O}_{2} / 5 \% \mathrm{CO}_{2}\right)$ solution containing $120 \mathrm{~mm}$ $\mathrm{NaCl}, 20.1 \mathrm{mM} \mathrm{NaHCO}, 5.0 \mathrm{~mm} \mathrm{KCl}, 1.25 \mathrm{mM} \mathrm{MgCl}_{2}, 1.6 \mathrm{~mm} \mathrm{CaCl}_{2}$, and $1.0 \mathrm{M}$ glucose $(\mathrm{pH} 7.4)$. The Plexiglas trough held a volume of $3 \mathrm{ml}$, which was maintained at $23 \pm 1^{\circ} \mathrm{C}$

Stimulation. Soleus was tested first by stimulating the soleus nerve with a suction or bipolar platinum wire electrode. During the second phase of in vitro testing, the muscle was bathed in Ringer's solution containing curare (d-tubocurarine chloride, 0.02 gm/liter; Sigma) and stimulated directly by passing current between two platinum plates placed on opposite sides of the muscle. The back surfaces of each plate were insulated with vacuum grease to minimize current spread to areas of the solution other than the muscle. The output of the stimulator was passed through an amplifier and an impedance-matched transformer to boost the magnitude of effective voltage corresponding to approximately $1.5 \mathrm{~A}$ being passed through the muscle and solution.

Mechanical measurements. Tension was measured using a variable capacitance torce transducer (Schilling, 1960) titted with a stainless steel hook extension. The resonant frequency of the transducer and its connections was $2.4 \mathrm{kHz}$. The compliance of this system was $150 \mu \mathrm{m} / \mathrm{kg}$. Muscle length and displacement were controlled by an LTV Ling Altec driver (model 408; compliance, $50 \mu \mathrm{m} / \mathrm{kg}$ ) similar to that used by Homsher and Rall (1973).

Soleus nerve or muscle was stimulated with a voltage pulse adjusted to 2 times the minimum voltage required to obtain a maximal twitch response. Muscle length was adjusted so that maximal twitch tension was produced. Isometric twitch tension $\left(P_{l}\right)$, time to peak twitch tension (TPT), relaxation time to half-peak twitch tension (Half-RT), isometric tension developed at 5 , $10,20,30,40,50,75$, and $100 \mathrm{~Hz}$ stimulation lasting $3 \mathrm{sec}$, and maximal rate of tension development $\left(d P_{0} / d t\right)$ were recorded.

Under conditions of direct stimulation and at a frequency $(50 \mathrm{~Hz})$ at which maximal isometric tetanic tension $\left(P_{o}\right)$ was produced, the velocity of unloaded shortening $\left(V_{u s}\right)$ was determined from a series of four contractions lasting 3 sec (Edman, 1979; Claflin and Faulkner, 1985). During steady-state isometric tetanus, the muscle was rapidly released to a shorter length at a rate of approximately $400 \mathrm{~mm} / \mathrm{sec}$ (Fig. 1). All releases for a given muscle were initiated from the same preset muscle length. This length was adjusted so that muscle length after shortening remained within the plateau region of the muscle's length-tension curve.

The time at zero tension was taken from the initial fall of tetanic tension to the deflection of the tension record from the base line produced by a passive release (unstimulated muscle) of equal magnitude. For weaker muscles, the deflection of the tension trace from base line was obscured by mechanical oscillations seen at very high gain. To determine the deflection point in a consistent manner, the muscle was released passively a given distance, and a straight horizontal line was drawn through the passive tension record. This served as the base line during which active tension was zero. Then, after an active release of identical magnitude, a second line was extrapolated back to the base line from the linear portion of the tension redevelopment curve, which occurred within the first 20 to $40 \mathrm{msec}$ of tension redevelopment. The intercept of the two lines was taken as the point at which tension began to redevelop.

Knowing the length of the excursion and the time at zero tension (see Fig. 1), a value for maximal velocity was derived. Shortening amplitudes for the four contractions were plotted againsl curresponding times at zero force, with the slope of the least squares regression line fit to these points representing $V_{u s}$. In addition, the intercept of the slope with the ordinate ylelded an estimate of the in series elasticity of the muscle (Edman, 1979).

Transducer outputs were monitored using an oscilloscope for display and photography, and were recorded on chart paper (Gould Recorder 2200) and FM tape (Vetter model B). Measurements of tension and $V_{u s}$ were analyzed directly from chart records or photographs of oscilloscope recordings. The $d P_{\text {o }} / d t$ was determined digitally using a computer (Digital, PDP-11) analysis of FM tapes sampling at a rate of $1 \mathrm{kHz}$.

\section{Histochemical analysis}

After weighing each muscle, cross-sections of approximately $5 \mathrm{~mm}$ thickness were taken from the muscle belly and frozen in isopentane cooled with liquid nitrogen. Thick sections $(10 \mu \mathrm{m})$ were cut serially at $-20^{\circ} \mathrm{C}$ and stained for myofibrillar ATPase activity with acid $(\mathrm{pH} 4.3)$ or alkaline $(\mathrm{pH} 9.8)$ preincubation and reduced nicotinamide adenosine dinucleotide diaphorase (NADH) activity (Maier et al., 1976). Histochemical fiber type percentages were determined using the classification scheme of Peter et al. (1972), which describes slow twitch-oxidative (SO), fast twitch-oxidative-glycolytic (FOG), and fast twitch-glycolytic fiber types. Using an image processing system (Castleman et al., 1984), cross-sectional areas of each fiber type were determined by digitizing the perimeters of 100 to 150 fibers from the central region of the muscle stained for alkaline myofibrillar ATPase. No differences in fiber type distribution were found between this region and peripheral areas of the muscle. The average fiber cross-sectional area (F-CSA) was calculated by summing the products of F-CSA for each fiber type times the percentage of that fiber type present within the muscle.

\section{Statistical analysis}

Multivariate analyses of variance or repeated measurcs analyscs of variance were used to examine statistical differences among experimental con- 

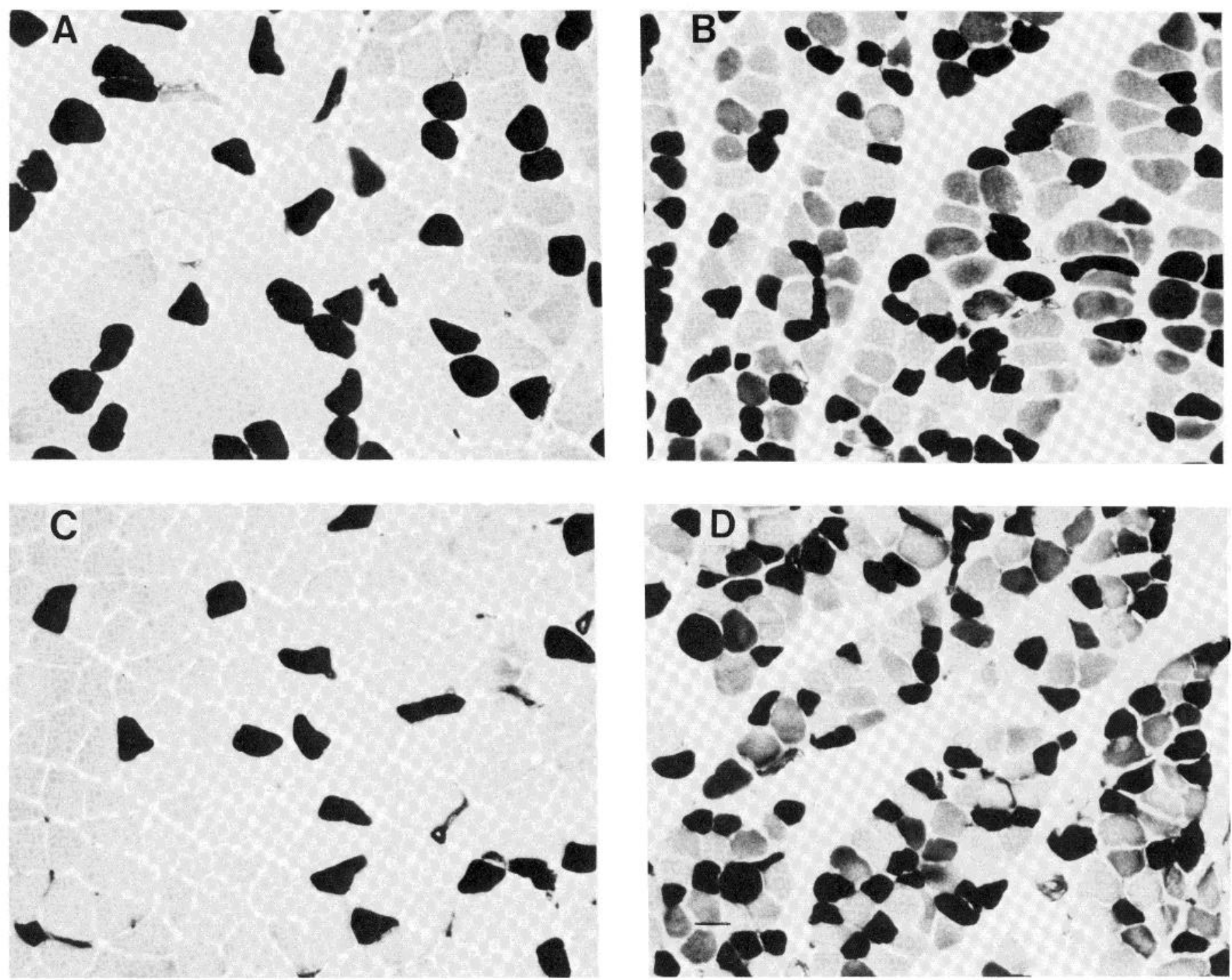

Figure 2. Photomicrographs of rat soleus histochemically stained for myofibrillar ATPase, preincubated at pH 9.8. Unoperated $(A)$, contralateral 2-week TTX-disused $(B)$, 4-week sham $(C)$, and contralateral TTX-disused $(D)$ muscles are shown. The calibration bar in $D$ (lower left) equals $50 \mu$ m.

ditions and times of treatment for each of the morphometric, speed, and tension parameters. A test for simple main effects was implemented for those parameters which showed a significant interaction between the independent variables, time, and experimental condition. Statistical significance was set at the $95 \%$ level of confidence. Numerical presentation of results is in the form of means \pm SEM for each experimental condition or time. It should be emphasized, however, that the statistical tests examine within animal differences between experimental conditions and across times of treatment rather than assessing degrees of variability across animals, which is reflected in values of SEM.

\section{Results}

The contractile and histochemical properties of bilaterally paired soleus muscles from three groups of animals were determined. In one group $(n=7)$, no differences were found in any mechanical or histochemical properties between unoperated muscles from right and left limbs. In a second group of rats in which untreated muscles were compared with contralateral sham TTX-treated muscles, no differences were seen after 2 or 4 weeks of treatment in muscle weight, twitch kinetics, twitch or tetanic tension, mean F-CSA, or histochemically determined fiber type distributions. One limb of a third group of rats was implanted with a TTX pump and nerve cuff contralateral to a sham or unoperated limb. Contractile and histochemical characteristics of sham or unoperated soleus muscles were not different from similarly treated muscles from the first or second group of rats.

Based on light microscopic examination of cross-sections of osmium-fixed and stained soleus or sciatic nerves from sham or TTX-operated limbs, there was no evidence of demyelination or apparent reductions in axonal number (see Betz et al., 1980, for similar results using this implantation technique). Light microscopic study of histologically stained pre- and postsynaptic components of synapses of two TTX-inactivated soleus muscles showed single synapses on every fiber examined on the surface of the muscle (S. A. Spector and M. S. Letinsky, unpublished observations). Finally, miniature endplate potentials were recorded from each of 30 surface muscle fibers studied in one 2-week TTX-treated soleus muscle (A. J. D'Alonzo and S. A. Spector, unpublished observations). Consequently, it was concluded that neither the surgical procedure nor any direct effect of TTX on the properties of the nerve or muscle studied resulted in effects that could be attributed to partial denervation or direct systemic effects of TTX on the muscle. As a result of the similarities in the different muscles, statistical analyses were performed on three categories of muscles: unoperated (control), sham cuff-operated (sham), and TTX-inactivated (TTX) muscles.

\section{Muscle morphology}

Changes in the gross morphology of soleus in response to 2 or 4 weeks of disuse are presented in Table I. Substantial atrophy, as 

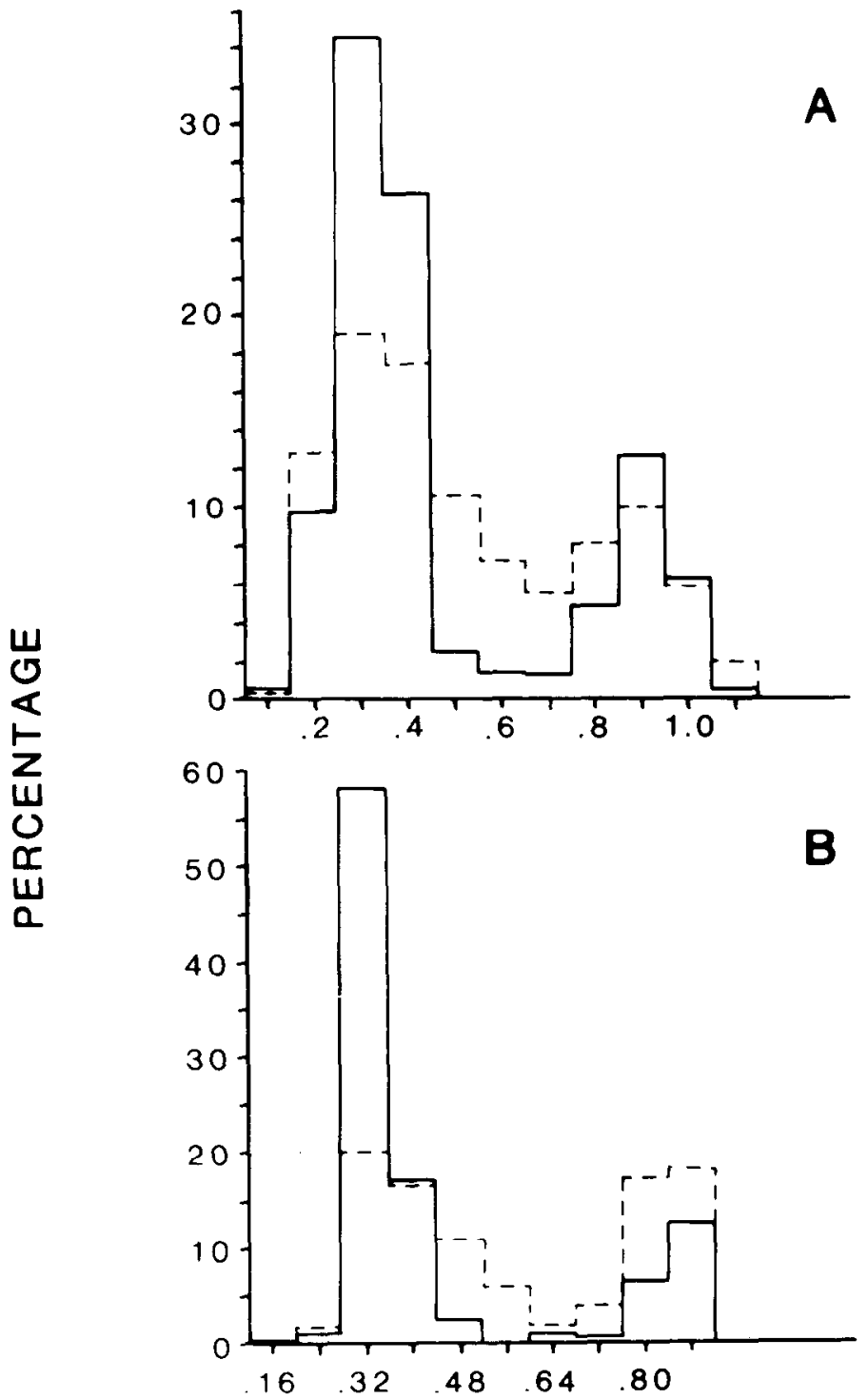

\section{ATPASE STAINING OPTICAL DENSITY}

Figure 3. Histogram distribution of myofibrillar ATPase (preincubation, $\mathrm{pH}$ 9.8)-staining intensities of fibers of sham (solid line) and TTX (dashed line) muscles after $2(A)$ or $4(B)$ weeks of treatment. Fiber type distributions for individual muscles in each experimental treatment were similar and, therefore, were combined to produce this histogram (2-week sham, 782 fibers from seven muscles; 2-week TTX, 1087 fibers from seven muscles; 4-week sham, 437 fibers from four muscles; 4-week TTX, 488 fibers from four muscles).

determined by wet muscle weight, was observed by the end of 2 ( $60 \%$ of sham) or 4 ( $45 \%$ of sham) weeks. Significant changes in muscle length were not seen in any experimental condition at either time, suggesting that the atrophy in the TTX muscles was primarily the result of a reduction in muscle cross-sectional area (Table I).

Representative cross-sections of control, sham, and TTX-disused muscle stained for myosin ATPase are shown in Figure 2. Mean F-CSA of these muscles was calculated to determine the extent to which this component of muscle cross-sectional area was affected by the TTX treatment. Compared to sham muscles fibers, the sizes of which were similar to those of control muscles, mean F-CSA of
TTX-trealed muscles was reduced to $53 \%$ and $28 \%$ of sham soleus after 2 or 4 weeks of inactivity, respectively.

The distribution of optical densities of fibers for alkaline preincubated ATPase in sham or TTX muscles is shown in Figure 3. These results, which combine all fibers for a given treatment or time, reflect the changes observed between these experimental conditions for individual pairs of muscles. A bimodal distribution based on mean staining optical density was found for sham soleus after 2 or 4 weeks of treatment. Fibers staining lightly for myosin ATPase (75 to $85 \%$ ) were classified as SO fibers (Table I) in conjunction with dense staining of all soleus fibers for $\mathrm{NADH}$ diaphorase. Fibers staining darkly for myosin ATPase ( 15 to $20 \%$ ) were characterized as FOG fibers. Using the same demarcation value of staining optical density for identifying SO and FOG populations in sham muscles, TTX soleus remained comprised of two distinct populations of fibers after 2 or 4 weeks of inactivity. The absolute maximum and minimum optical densities of staining were not altered with either time of treatment. In addition, the mean ATPase density of staining of SO fibers was increased, whereas the mean staining density of FOG fibers was reduced. Thus, TTX soleus was comprised of significantly lower percentages of SO fibers ( $68 \%$ or $59 \%$ of sham, respectively) after 2 or 4 weeks of inactivity (Table 1). Measurements of mean F-CSA showed similar degrees of atrophy of SO and FOG fibers after 2 or 4 weeks of disuse (Table I).

\section{Muscle mechanics}

Nerve stimulation. Typical mechanical responses of sham (or control) and TTX soleus in response to in vitro stimulation of the soleus nerve at various frequencies are illustrated in Figure $4 A$. In addition, the average relationship between stimulation frequency and force in TTX and sham muscles after 2 or 4 weeks is shown in Figures $5 A$ and $6 A$ (dashed lines). Force output of nerve-stimulated TTX muscles was significantly diminished at all frequencies, being least affected at $1 \mathrm{~Hz}$ (35\% and $25 \%$ of control at 2 and 4 weeks, respectively). For all $T T X$ muscles studied, peak tension was generated at $20 \mathrm{~Hz}$, whereas sham muscle produced maximum tensions at frequencies between 40 and $75 \mathrm{~Hz}$. The twitch-to-tetanus ratio of nerve-stimulated muscle increased from 0.23 in sham muscles 10 0.55 by the end of 2 weeks of TTX treatment, and from 0.20 for sham to 0.36 for TTX muscle at 4 weeks.

The relation between stimulation frequency and tension, expressed relative to force produced at $20 \mathrm{~Hz}$, is plotted in Figures $5 B$ and $6 B$. At frequencies less than $20 \mathrm{~Hz}$, nerve-stimulated TTX soleus produced more force, relative to its maximal potential, than did control soleus muscles. However, at frequencies above $20 \mathrm{~Hz}$, TTX muscles became more impaired in producing tension. This effect is illustrated clearly in the tension records of Figure $4 A$, which show depressions in tension with stimulation at $20 \mathrm{~Hz}$ or higher.

Mechanical indices related to the speed of twitch or tetanic contractions of soleus stimulated through the soleus nerve are listed in Table II. Changes in the speed of the twitch response (TPT or Half-RT) were not found after 2 or 4 weeks of inactivation. The maximum rate at which tetanic tension developed was significantly depressed at $20 \mathrm{~Hz}\left(d P_{20} / d t\right)$ and $50 \mathrm{~Hz}\left(d P_{o} / d t\right)$. At the end of 2 or 4 weeks of treatment, rate of tension development expressed relative to the maximal tension was enhanced substantially with either $20 \mathrm{~Hz}$ or $50 \mathrm{~Hz}$ stimulation.

Direct stimulation. The response of directly stimulated sham or TTX soleus is typified by the tension records of Figure $4 B$; the average tension responses of these muscles are plotted against stimulation frequency after 2 or 4 weeks in Figures $5 A$ and $6 A$ (solid lines). As observed with nerve stimulation, absolute tension of directly stimulated TTX soleus was substantially reduced at all frequencies of stimulation after 2 or 4 weeks of treatment. However, in contrast to nerve stimulation, TTX soleus was capable of generating greater amounts of tension at frequencies higher than $20 \mathrm{~Hz}$. In fact, when tension developed at a given frequency was expressed relative to tension developed at $20 \mathrm{~Hz}$ (Figs. $5 B$ and $6 B$ ), it became 


\section{STIMULATION FREQUENCY (Hz)}

\section{$510203040 \quad 50100$}

A

Figure 4. Records of isometric tension developed at various frequencies of stimulation in response to nerve $(A)$ or direct $(B)$ stimulation of a 2 -week treated pair of muscles. Soleus nerves of both sham and TTX muscles were stimulated with $0.1-\mathrm{msec}$ square wave pulses less than $10 \mathrm{~V}$, which yielded maximal tetanic responses. Sham soleus was directly stimulated maximally with 0.5 -msec pulses of approximately 30 $V$. TTX-treated soleus was stimulated with 0.5 -msec pulses of about $60 \mathrm{~V}$, which produced near-maximal tension (see the text).

\author{
NERVE \\ STIMULATION \\ B

DIRECT
STIMULATION

clear that the relative tension-producing capabilities of soleus at frequencies above $20 \mathrm{~Hz}$ were comparable to sham soleus stimulated directly or by its nerve.

It was not always possible to achieve a maximal twitch or tetanic tension response under conditions of direct in vitro stimulation. Such affects have been reported for chronically denervated cat (Kean et al., 1974) and rat (Drachman and Johnston, 1975; Finol et al., 1981) soleus muscle. In Figure 7 ( $A$ and $B$ ), twitch and tetanic tension responses of two 2-week TTX-treated soleus muscles are plotted against voltage (100 V across the stimulating electrodes was equivalent to passing approximately 1.0 A current through the muscle bath). Clearly, the amount of twitch or tetanic tension developed in TTX-disused muscle depended on both amplitude and duration of the voltage pulse. With higher voltages, the muscles responded abnormally during the relaxation phase of both the twitch and tetanus (see insets of Fig. 7, $A$ and $B$, for examples of tetanus). In fact, at the highest voltages tested, the muscle became irreparably damaged mechanically. Subsequent stimulation of the muscle, even after prolonged periods of rest, always produccd only a fraction of tension developed initially. Because extrapolation of the tension-voltage curves did not lead to further increases in tension greater than about $10 \%$, it was concluded that about $90 \%$ of tetanic tension was probably generated with direct stimulation.

Although this abnormal mechanical behavior was not examincd further, at least two explanations are possible. Relative increases in collagen content and enzymes associated with connective tissue synthesis are found in chronically denervated muscle (Garcia-Bunuel and Garcia-Bunuel, 1980). Based on the morphological data presented in Table I, it is probable that TTX-inactive muscle contains a disproportionately greater extracellular volume than intrafiber volume compared with normal muscles. This could effectively impede the flow of current into the core of the muscle.

In addition, electrical excitability of muscle has been shown to be diminished with chronic denervation. The increase in muscle fiber membrane resistance (Albuquerque and Thesleff, 1968) is due to reduced sodium permeability (McArdle et al., 1980). The relative increase in internal sodium concentration reduces the ionic gradient for production of the action potential (McArdle et al., 1980). Also, membranes of denervated fibers are depolarized significantly (Albuquerque and Thesleff, 1968; McArdle et al., 1980). As a result, the threshold for development of the action potential in denervated muscle fibers is increased, and the rate of rise and the overshoot of the spike are reduced (Redfern and Thesleff, 1971; Lewis, 1972; McArdle et al., 1980). Although membranes of TTX-disused muscle fibers are depolarized by between 10 and $15 \mathrm{mV}$ after 2 to 3 weeks (Bray et al., 1979; A. J. D'Alonzo and S. A. Spector, unpublished observations), other pertinent biochemical and electrophysiological measurements of TTX-disused muscle are not yet available. However, similarities in mechanical behavior of TTX and denervated muscle (Spector, 1985) suggest that the inherent excitability of TTXdisused muscles may be reduced similarly.

To avoid the mechanical damage seen with very high voltages, while exciting as much of the muscle are possible, square wave pulses of about $60 \mathrm{~V}$ lasting $0.5 \mathrm{msec}$ were used to stimulate TTXtreated muscles. The relation between maximal tetanic tension developed by directly stimulated soleus and various morphological indices is illustrated in Figure 8. Compared to control muscles, absolute tension of TTX-treated soleus was diminished to $26 \%$ and $14 \%$ after 2 or 4 wecks of treatment, respectively. Thesc deficits in tension cannot be explained completely by muscle atrophy, because there was a significant reduction in tension expressed per muscle weight, muscle cross-sectional area, or F-CSA.

As typified by the records of Figure 9, the time course of the twitch response to direct stimulation was found in the majority of muscles ( 9 of 12) to be dependent upon the amplitude and width of the voltage pulse. Thus, it was not always possible to achieve a value for TPT or Half-RT which reflected activation of the whole muscle. Using the same stimulation criteria for defining the twitch and tetanic lension responses for control, sham, and TTX muscles, the speed-related characteristics of soleus in response to direct 


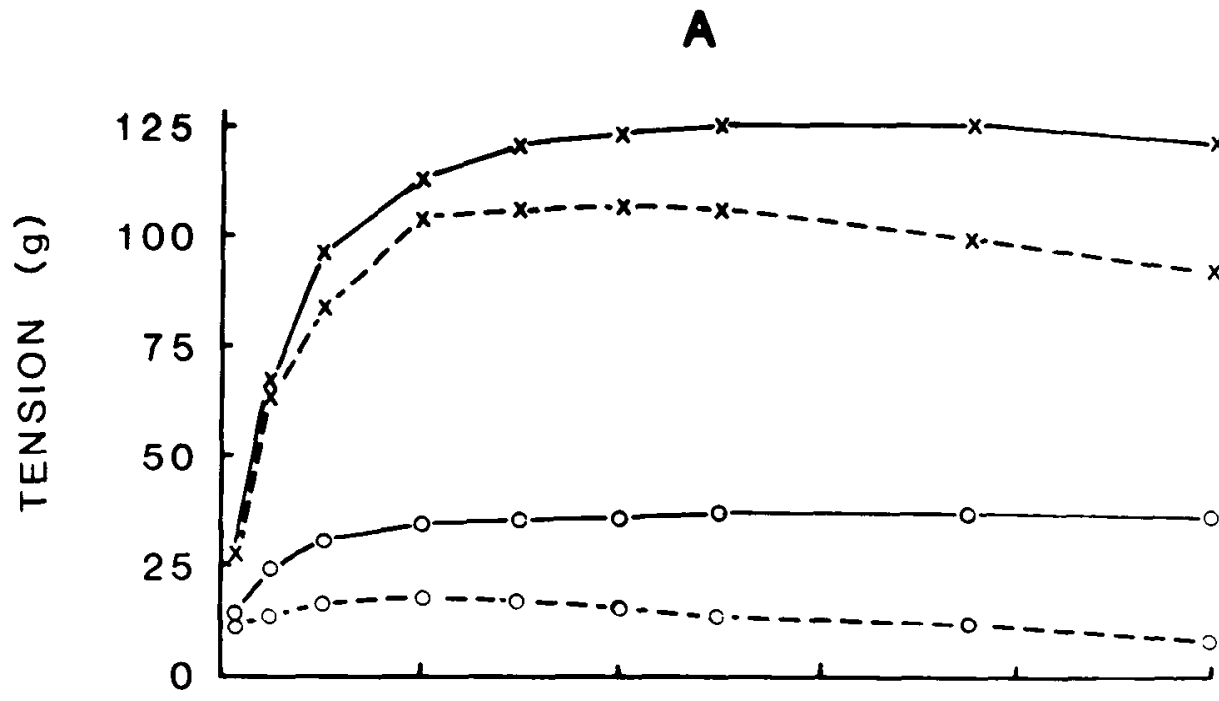

B

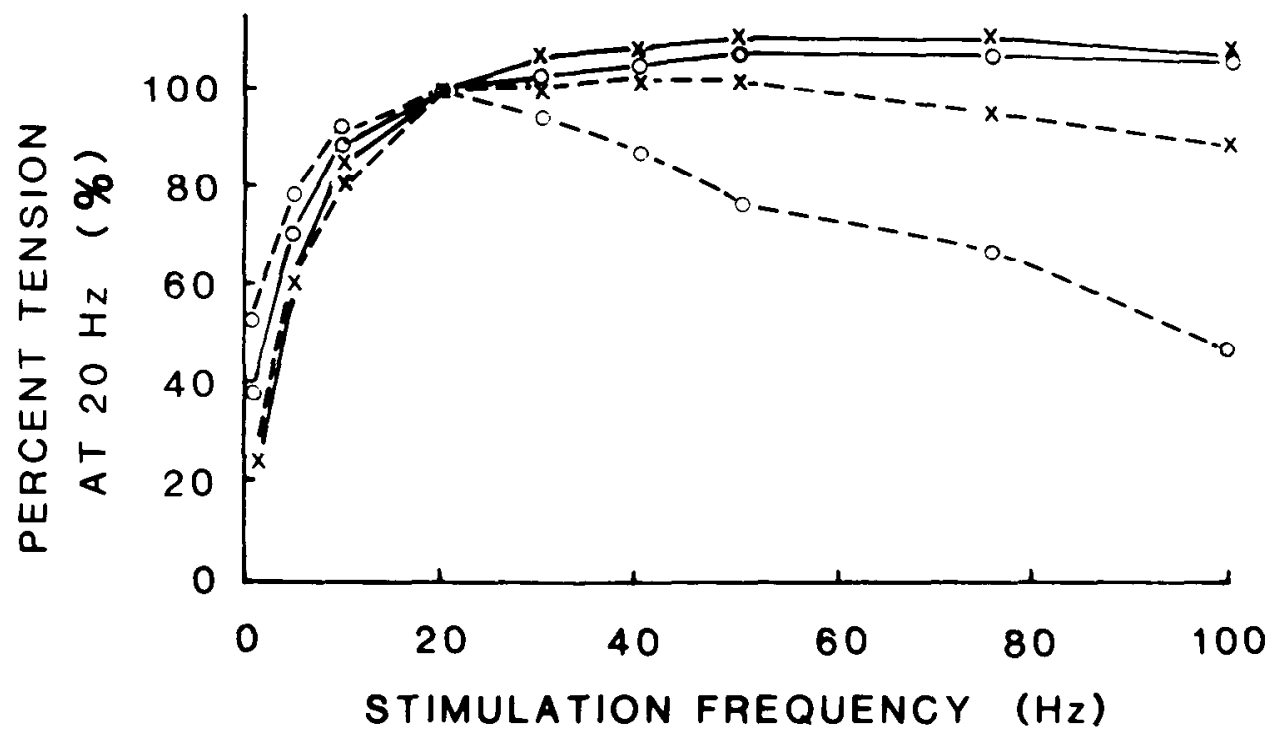

Figure 5. Average relation between isometric tension and frequency of stimulation of sham $(X)$ and TTX $(O)$ muscles with nerve $(--)$ or direct $(-)$ stimulation after 2 weeks of treatment. The stimulation protocol was the same as in Figure 4. In A, absolute tension is plotted against stimulation frequency; in $B$, tension developed at a particular frequency is expressed relative to that muscle's tension response at $20 \mathrm{~Hz}$.

stimulation were determined (Table III). As with nerve stimulation, no differences in TPT were found between TTX and sham or control muscles after 2 or 4 weeks of treatment. The Half-RT of TTX soleus was prolonged significantly at 2 weeks, although signiticant differences were not seen at 4 weeks. Absolute $d P_{o} / d t$ of TTX soleus was significantly reduced, although when expressed relative to maximal tension, the rate of tension development increased by $38 \%$ and $43 \%$ after 2 and 4 weeks, respectively.

To obtain a closer representation of the intrinsic speed of rat soleus, the maximal rate at which the muscle could shorten when virtually unloaded (see Fig. 1) was measured (Table III). After 2 weeks of TTX inactivity, the velocity of unloaded shortening $\left(V_{u s}\right)$ was significantly increased compared with contralateral sham muscles. The differences between TTX and control muscles taken from another group of rats were not significant. By 4 weeks, however, $V_{u s}$ of TTX soleus was substantially increased, whether compared to sham or control muscles.

\section{Discussion}

It has been well established by the cross-reinnervation experiments of Buller et al. (1960) and others (Close, 1969; Barany and Close, 1971: Chan et al., 1982) that many properties of whole muscle or motor units are influenced by the innervating motoneuron.
Experiments implementing exercise training (Saltin and Gollnick, 1983) or electrical stimulation (Salmons and Sreter, 1976) suggest that the muscle cell's characteristics are mediated through changes in neuromuscular activity, although additional studies implicate a potential neurotrophic effect, as well (Gutmann, 1976; McArdle, 1983). Presently, the influence of nerve-evoked activity on morphological, contractile, and histochemical characteristics of rat slow twitch muscle was assessed, not through experimental manipulation of the amount or quality of activity, but by the complete elimination of this stimulus from an innervated neuromuscular system.

Morphological characteristics. Extensive atrophy of rat soleus occurred after chronic TTX treatment, presumably due to reduced rates of synthesis and/or increased degradation rates of muscle proteins. Reductions in muscle mass after 2 weeks (60\% of control) were similar to decreases in average fiber size $(53 \%$ of control). By the end of 4 weeks of treatment, however, the substantial decreases in fiber size ( $28 \%$ of control) were less reflective of whole muscle atrophy ( $45 \%$ of control), suggesting that there were disproportionate decreases in fiber volume relative to extrafiber components.

Decreases in muscle mass and fiber size in slow or fast twitch muscle have been observed after chronic tenotomy, immobilization, cordotomy, or hindlimb suspension (Eccles, 1944; Karpati and Engel, 1968; Maier et al., 1976; Johnson et al., 1982; Spector et al., 


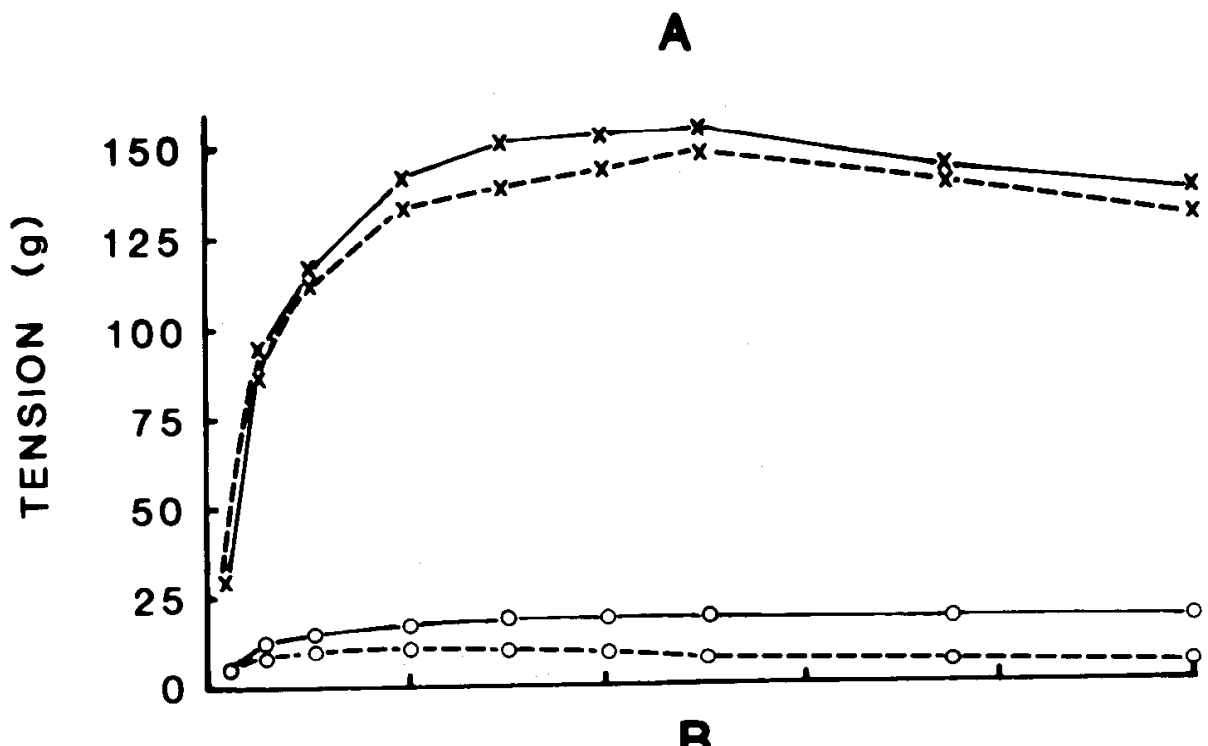

Figure 6. Same as Figure 5, except the relationships represent 4 -week treated muscles.

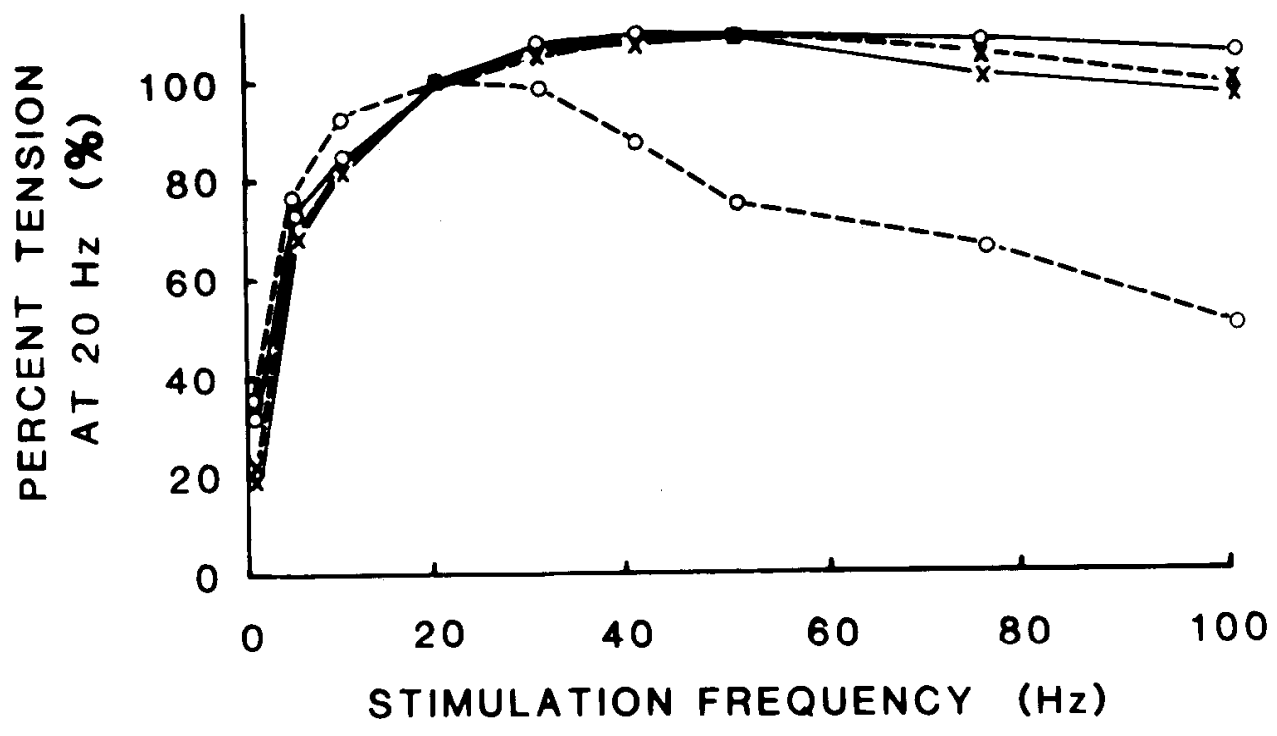

TABLE \|

Speed-related properties of nerve-stimulated rat soleus after 2 or 4 weeks of $T$ TX inactivation

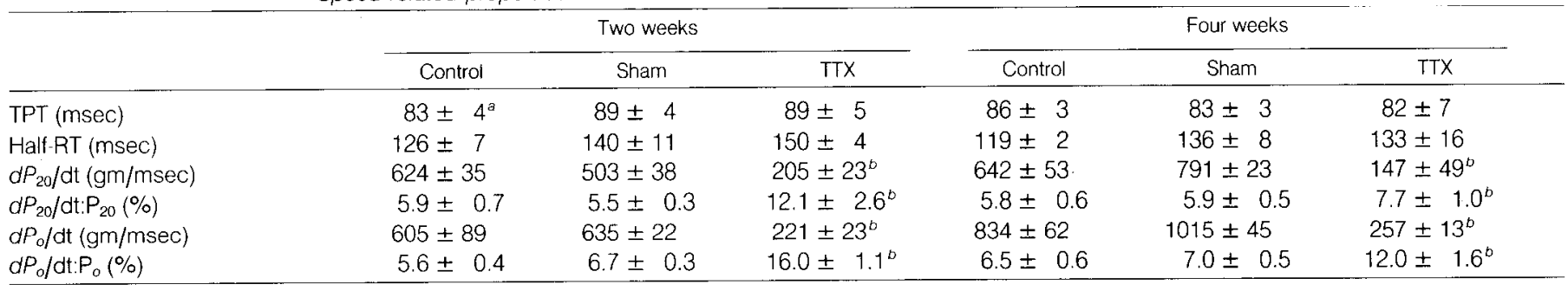

${ }^{a}$ Values are means \pm SEM.

${ }^{\circ}$ Significant difference between TTX and sham or control. Sample sizes are the same as in Table I.

1982; Musacchia et al., 1983), although these atrophic responses were less than those seen for TTX-disused rat soleus. The aggregate electromyographic activity which remains in muscles of these other treatments might explain their reduced amounts of atrophy compared with TTX disuse. However, differences in the amount of passive tension, as well as the types of contractions that the animals may still generate (isometric, unloaded, at extreme muscle lengths) in these "reduced activity" models may also influence the extent of atrophy. The relative effects of these additional influences on atrophy are seen, for example, in muscle immobilized at extreme lengths (Goldspink, 1977; Spector et al., 1982) or stimulated tenotomized muscle (Eccles, 1944). In the present experiment, no evidence of electrical activity in TTX-disused muscles was found. In addition, in vitro determination of muscle lengths of TTX-treated soleus were not significantly different from normal. Therefore, the degree of atrophy of these muscles probably was not influenced by any residual neuromusciular activity or abnormal passive tension development.

The possibility cannot be excluded that the atrophic response of 
A
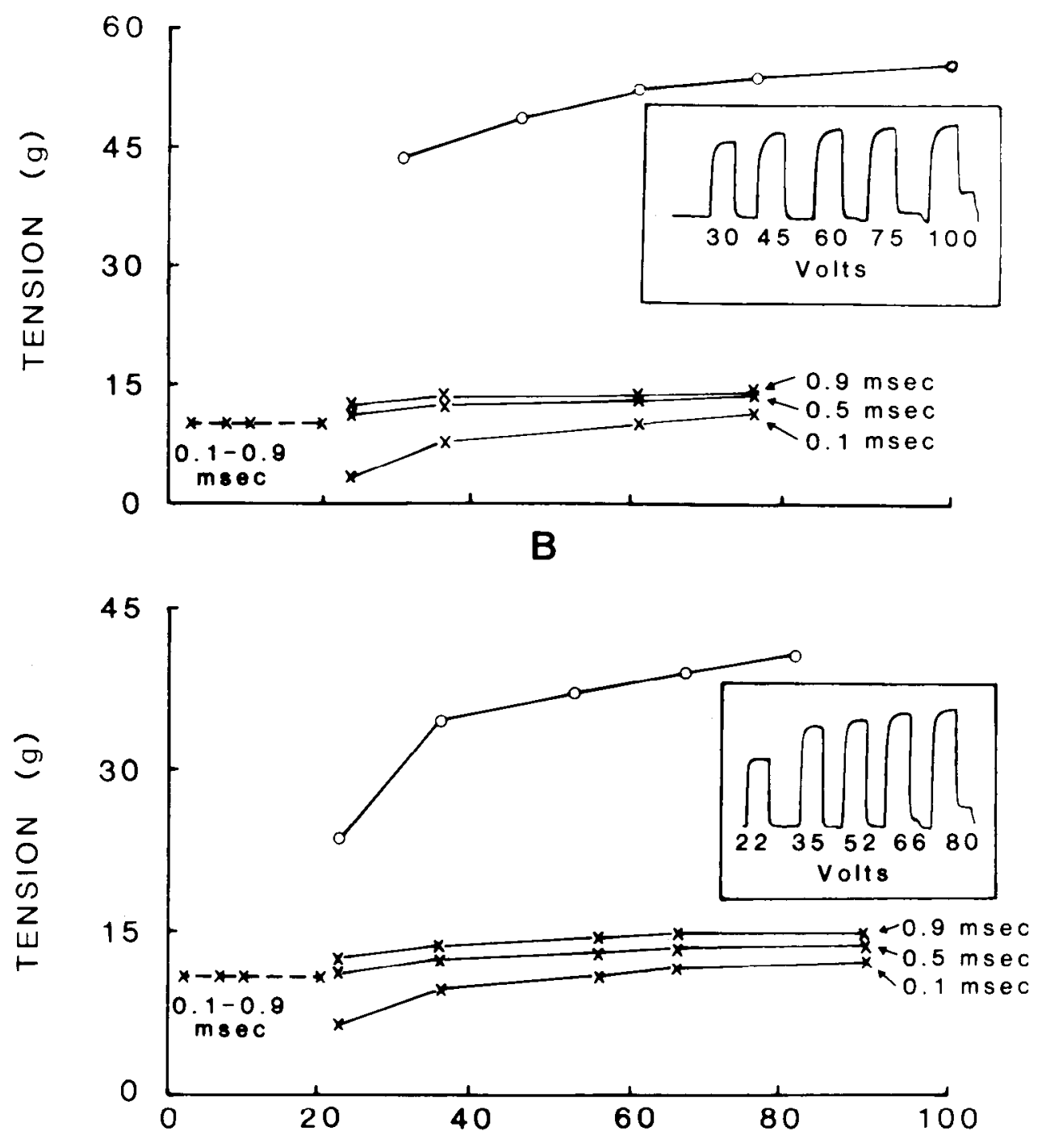

Figure 7. Relation between twitch $(X)$ or tetanic $(\mathrm{O} ; 50 \mathrm{~Hz})$ tension developed at various amplitudes of voltage in response to nerve $(---)$ or direct $(-)$ stimulation of TTX soleus for varied stimulus durations. A and $B$ represent two examples of 2-week treated muscles. Insets are actual tetanic tension records as voltage amplitude of a 0.5 -msec pulse is varied.

\section{VOLTAGE ( $V$ )}

soleus resulted from changes in the production or release of a putative neurotrophic factor associated normally with neurally evoked synaptic activity. In addition, changes in membrane properties of the motoneuron initiated by inactivity (Czeh et al., 1978) could modify the production or release of a trophic substance. However, direct evidence for such effects has not been demonstrated. Consideration of systemic hormonal or humoral interactions upon the response of these muscles was obviated as direct bilateral comparisons between TTX-disused and sham muscles were made. These arguments support the contention that the extent of atrophy seen in this TTX preparation is probably the sole result of elimination of neuromuscular activity.

Tension-related characteristics. Deficits in maximal tension produced by TTX-treated soleus were greater than the extent of atrophy as assessed by muscle weight, whole muscle, or fiber crosssectional area. Reductions in tension per muscle weight have been reported in slow and fast twitch muscles of adult cordotomized (Johnson et al., 1982), tenotomized (Eccles, 1944), or spinal-isolated (Eldridge and Mommaerts, 1981) cat soleus, and rat slow and fast twitch muscle immobilized in a chronically shortened position (Simard et al., 1982). In contrast, skeletal fixation at neutral joint angles did not affect tension per muscle weight of rat hindlimb muscles (Spector et al., 1982), whereas increases have been observed in fast twitch muscles of the guinea pig, rabbit, and bushbaby (Fischer and Ramsey, 1944; Edgerton et al., 1975; Maier et al., 1976).

Tension per muscle weight could be influenced by disproportionate changes in extracellular volume in these various experimental treatments. Tension related directly to mean fiber size minimizes this effect. Tension expressed per mean F-CSA of TTX-disused soleus of the rat was reduced by more than $30 \%$ after 2 or 4 weeks of treatment, a result that could be explained by increases in the ratios of sarcoplasmic to contractile components within individual muscle fibers, impairment of the contractile activation system, or the inability under the present in vitro conditions of stimulation to maximally activate the muscle.

An interesting finding was the depression of the tetanic tension of TTX-disused soleus when stimulated via the nerve at frequencies between 20 and $100 \mathrm{~Hz}$. Similar responses were occasionally seen in sham or control soleus, but at frequencies 3 to 5 times higher than needed to produce this response in TTX muscles. High frequency stimulation (Curtis and Eccles, 1960; Kuno, 1964) resulted in depression of intracellularly recorded postsynaptic responses due to either presynaptic or synaptic failure (Krrjevic and Miledi, 1959; Hatt and Smith, 1976). This behavior was observed in normal 


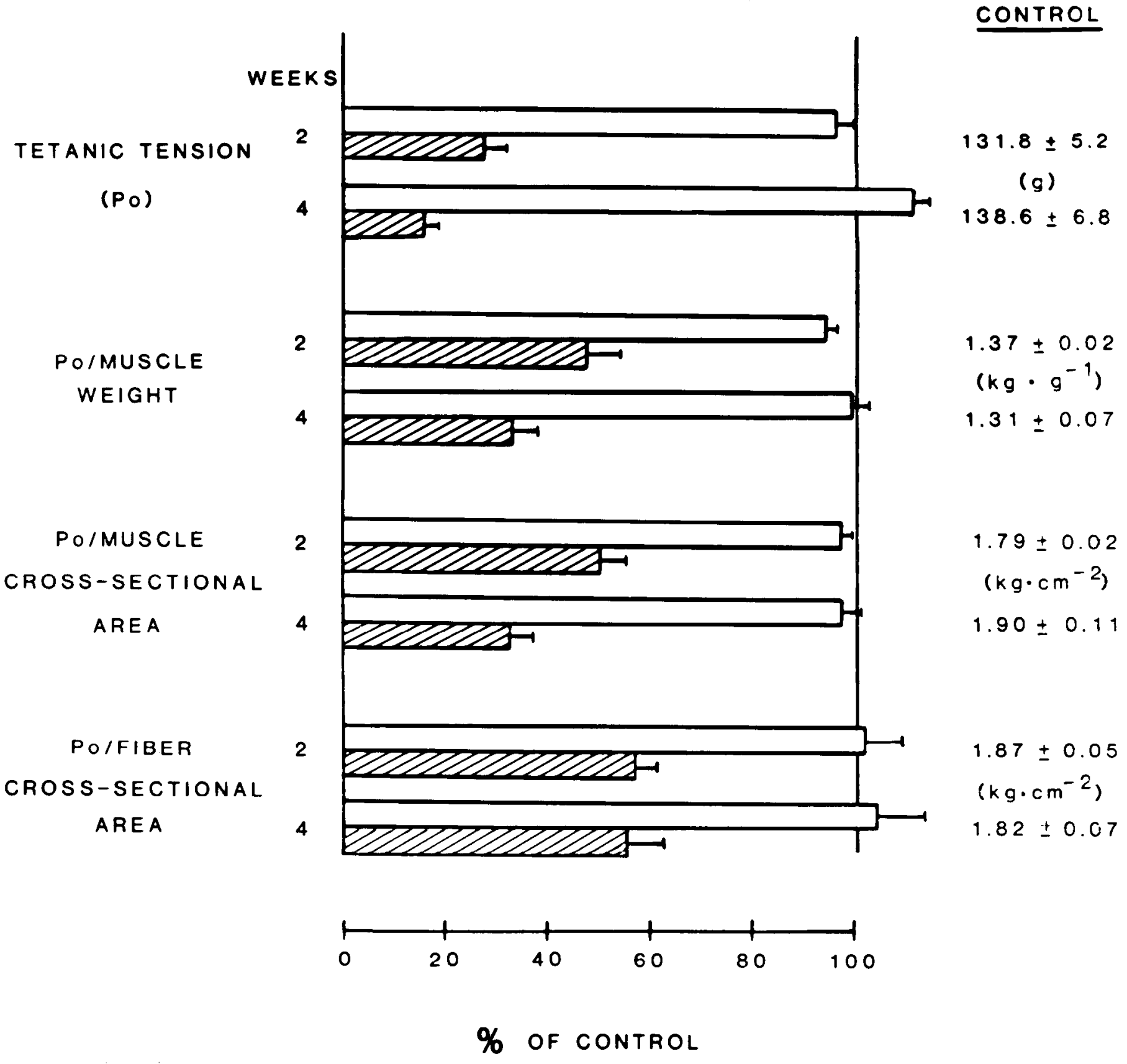

Figure 8. Maximal letanic tension $\left(P_{o}\right)$ and $P_{o}$ related lo specilic morphological parameters listed in Table I, ur sh larn (open bars) and TTX (stippled bars) muscles expressed as a percentage of control means \pm SEM after 2 or 4 weeks of treatment. Absolute values for control soleus are to the right of the bars. All TTX values were significantly different from sham or control values. Values for fiber cross-sectional area were derived by multiplying mean F-CSA (Table 1) by an approximation of the number of muscle tibers in normal soleus (3000; Gollnick et al., 1981).

TABI F III

Speed-related properties of directly stimulated rat soleus after 2 or 4 weeks of $T \mathrm{X}$ inactivation

\begin{tabular}{|c|c|c|c|c|c|c|}
\hline \multirow[b]{3}{*}{ TPT (msec) } & \multicolumn{3}{|c|}{ Two Weeks } & \multicolumn{3}{|c|}{ Four Weeks } \\
\hline & Control & Sham & $\pi x$ & Control & Sham & $\pi x$ \\
\hline & $85 \pm 4^{a}$ & $84 \pm 4$ & $92 \pm 5$ & $78 \pm 4$ & $81 \pm 1$ & $79 \pm 4$ \\
\hline Half-RT (msec) & $115 \pm 6$ & $128 \pm 7$ & $169 \pm 8^{b}$ & $122 \pm 7$ & $136 \pm 6$ & $130 \pm 14$ \\
\hline$d P_{o} / \mathrm{dt}(\mathrm{gm} / \mathrm{msec})$ & $770 \pm 61$ & $704 \pm 52$ & $287 \pm 47^{\circ}$ & $890 \pm 52$ & $1053 \pm 105$ & $208 \pm 66^{b}$ \\
\hline$d P_{o} / d t: P_{o}(\%)$ & $5.9 \pm 0.2$ & $5.8 \pm 0.4$ & $8.0 \pm 0.7^{\circ}$ & $6.4 \pm 0.3$ & $6.5 \pm \quad 0.5$ & $9.3 \pm 0.6^{b}$ \\
\hline$V_{u s}(\mathrm{~mm} / \mathrm{sec})$ & $53.4 \pm 2.7$ & $47.6 \pm 3.3$ & $66.6 \pm 6.8^{c}$ & $60.1 \pm 5.7$ & $60.7 \pm 1.0$ & $73.2 \pm 5.5^{b}$ \\
\hline
\end{tabular}

${ }^{a}$ Values are means \pm SEM. Sample sizes are the same as in Table 1 .

${ }^{b}$ Significant difference between TTX and sham or control.

${ }^{\mathrm{c}}$ Significant difference betwecn TTX and sham only 


\section{TTX (2 WEEKS - DIRECT STIMULATION)}
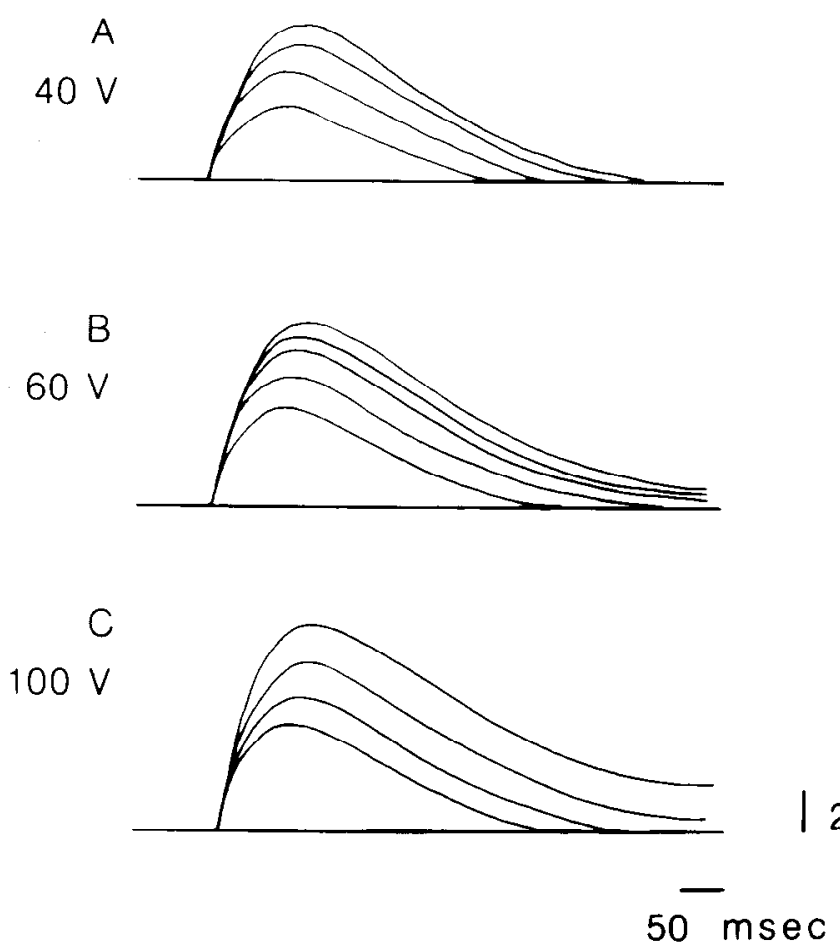

Figure 9. Hand-traced records of twitch responses of 2-week TTX-inactivated soleus to direct stimulation of $40 \vee(A), 60 \vee(B)$, and $100 \vee(C)$. For each panel, the pulse width was varied while voltage amplitude was held constant. Beginning with the lowest twitch tension response, pulse width was increased successively $(0.1 \mathrm{msec}, 0.3 \mathrm{msec}, 0.5 \mathrm{msec}, 0.7 \mathrm{msec}, 0.9$ $\mathrm{msec}$ ). In $A$, the twitch response to a $0.1-\mathrm{msec}$ pulse is not detectable on the trace. In $C$, a $0.9-$ msec pulse was not attempted.

mammalian systems incubated at room temperature (Krnjevic and Miledi, 1959) and would explain the depression in force of sham or control muscles stimulated at $100 \mathrm{~Hz}$ (at $23^{\circ} \mathrm{C}$ ). The tetanic depression of TTX-disused soleus muscle was not only more pronounced at the higher frequencies studied but was evident at much lower frequencies, as well, suggesting that the elimination of neuromuscular activity accentuates tetanic depression of this muscle. In the phrenic nerve-diaphragm preparation of aged rat, nerve conduction blockade due to high frequency stimulation of several minutes occurred at an earlier time and at a lower frequency than in young controls (Smith, 1979). In addition, tension responses of neonatal rat soleus maintained in vitro at $23^{\circ} \mathrm{C}$ were strikingly similar in the level of tetanic depression for a given frequency (Thompson, 1983) to those produced by TTX-disused muscles in the present study. Also, the high frequency depression of tetanic responses seen in rabbit soleus tenotomized for 2 months was abolished completely when the muscle was stimulated directly in a solution containing curare (Bagust, 1979). Whether the deficits in neural transmission and therefore, in contractile behavior of TTX-disused soleus are produced by the same factor(s) responsible for these responses in neonatal, aged, or tenotomized neuromuscular synapses is not known.

Speed-related characteristics. The present results indicate that the changes in the percentage distributions of fiber types of TTX. inactivated soleus reflect simply the gradual conversion of larger numbers of $\mathrm{SO}$ fibers to those classified as FOG fibers (i.e., exhibiting optical densities greater than 0.65 units) with time. By the end of 4 weeks of TTX treatrnent, rat soleus was comprised of about $20 \%$ more FOG fibers than are seen normally. Similarly, the presence of FOG fibers in an otherwise exclusively slow twitch muscle has been observed in cordotomized or immobilized cat and guinea pig soleus (Karpati and Engcl, 1968; Maicr ot al., 1976; Johnson et al., 1982), whereas a substantial increase in FOG fibers was reported in the slow twitch rat soleus after 4 weeks of immobilization (Booth and Kelso, 1973). The present results, therefore, are consistent with the hypothesis that neuromuscular disuse plays some role in the histochemical transformations of fiber types.

The question of whether the increase in FOG fibers in TTX inactivated soleus is reflected in mechanical alterations in contraction speed could be addressed in the present study by estimating the muscle's speed-related properties under both isometric and dynamic conditions. With either nerve or direct stimulation, parameters related to the time course of the twitch (TPT; Half-RT) were not significantly altered after 2 or 4 weeks of TTX disuse (except Half-RT in 2-week field-stimulated soleus). However, in this study (Fig. 9), the time course of the twitch was altered substantially when either the width or amplitude of the stimulation pulse was changed. This questions the reliability of twitch time as a measure of contractile function under the present conditions.

In contrast to the twitch, $d P_{\mathrm{o}} / d t$ in response to field stimulation was substantially higher than in sham or control soleus when expressed relative to maximum tension developed at $50 \mathrm{~Hz}$. In association with the enhanced rate of tension development was the significant increase in $V_{u s}$ of TTX soleus compared to contralateral sharn muscles after 2 or 4 weeks of inactivation. Similarly, Close (1964) found a high correlation between these mechanical measures in rat slow and fast twitch muscles during development. Therefore, although twitch responses could not be used as reliable indicators of contractile function of TTX-disused muscle, other isometric and dynamic mechanical indices offered evidence that the underlying biochemical processes responsible for maximal rate of shortening were modified with chronic inactivity. These mechanical alterations of TTX-inactivated muscle, therefore, are consistent with the changes in histochemical profile of soleus which occur with chronic inactivity, and suggest that the elimination of neuromuscular activity leads to significant changes in the phenotypic expression of contractile properties of rat soleus muscle.

\section{References}

Albuquerque, E. X., and S. Thesleff (1968) A comparative study of membrane properties of innervated and chronically denervated fast and slow muscle of the rat. Acta Physiol. Scand. 73: 471-480.

Aliamo, M. A., J. L. Smith, R. R. Roy, and V. R. Edgerton (1984) EMG activity of slow and fast extensors following spinal cord transection. J. Appl Physiol. 56: 1608-1613.

Bagust, J. (1979) The effects of tenotomy upon the contraction characteris tics of motor units in rabbit soleus muscle. J. Physiol. (Lond.) 290: 1-10.

Barany, M., and R. Close (1971) The transformation of myosin in crossreinnervated rat muscles. J. Physiol. (Lond.) 213: 455-474.

Betz, W. J., J. H. Caldwell, and R. R. Ribchester (1980) Sprouting of active nerve terminals in partially inactive muscles of the rat. J. Physiol. (Lond.) 303: 281-297

Booth, F. W., and J. R. Kelso (1973) Eflect of hind-limb immobilization on contractile and histochemical properties of skeletal muscles. Pfiugers Arch. 342: $231-238$

Bray, J. J., J. I. Hubbard, and R. G. Mills (1979) The trophic influence of terodotoxin-inactive nerves on normal and reinnervated rat skeletal muscle. J. Physiol. (Lond.) 297: 479-491.

Buller, A. J., J. C. Eccles, and R. M. Eccles (1960) Interactions between motoneurones and muscles in respect to the characteristic speeds of their responses. J. Physiol. (Lond.) 150: 417-439.

Castleman, K. R., L. A. Chui, T. P. Martin and V. R. Edgerton (1984) Qualitative muscle biopsy analysis. Monogr. Clin. Cytol., in press.

Chan, A. K., V. R. Edgerton, G. E. Goslow, Jr., H. Kurata, S. A. Rasmussen, and S. A. Spector (1982) Histochemical and physiological properties of cat motor units after self- and cross-reinnervation. J. Physiol. (Lond.) 332: 343-361.

Claftin, D. R., and J. A. Faulkner (1985) Shortening velocity extrapolated to 
zero load and unloaded shortening velocity of whole rat skeletal muscle. J. Physiol. (Lond.) 359: 357-363.

Close, R. (1964) Dynamic properties of fast and slow skeletal muscles during development. J. Physiol. (Lond.) 173: 74-95

Close, R. (1969) Dynamic properties of fast and slow skeletal muscles of the rat after nerve cross-reunion. J. Physiol. (Lond.) 204: 331-346.

Close, R. I (1972) Dynamic properties of mammalian skeletal mısc.e. Physiol Rev. 52: 129-197.

Curtis, D. R., and J. C. Eccles (1960) Synaptic action during and after repetitive stimulation. J. Physiol. (Lond.) 150: 377398

Czeh, G., R. Gallego, N. Kudo, and M. Kuno (1978) Evidence for the maintenance of motoneurone properties by muscle activity. J. Physiol. (Lond.) 281: 239-252

Drachman, D. B., and D. M. Johnston (1975) Neurotrophic regulation of dynamic properties of skeletal muscle: Effects of botulinum toxin and denervation. J. Physiol. (Lond.) 252: 657-66\%

Eccles, J. C. (1944) Investigations on muscle atrophies arising from disuse and tenotomy. J Physiol. (Lond ) 103: 253-266.

Edman, K. A. P. (1979) The velocity of unloaded shortening and its relation to sarcomere length and isometric force in vertebrate muscle fibres. J. Physiol. (L.ond.) 291: 143-159.

Edgerton, V. R., R. J. Barnard, J. B. Peter, A. Maier, and D. R. Simpson (1975) Properties of immobilized hind-limb muscles of the Galego sene galensis. Exp. Neurol. 45: 115-131.

Eldridge, L., M. Liebhold, and J. H. Steinbach (1981) Alterations in cat skeletal neuromuscular junctions following prolonged inactivity. J. Physiol. (Lond.) 313. 529-545.

Finol, H. J., D. M. Lewis, and R. Owens (1981) The effects of denervation and contractile properties of rat skeletal muscle. J. Physiol. (Lond.) 319 $81-92$

Fischer, E., and V. W. Ramsey (1944) Changes in muscle proteins during muscular atrophy. Arch. Phys. Ther. 25: 709-716.

Fischbach, G. D., and N. Robbins (1969) Changes in contractile properties of disused soleus muscle. J. Physiol. (Lond.) 201: 305-320

Fournier, M., R. R. Roy, H. Perham, C. P. Simard, and V. R. Edgerton (1983) Is limb immobilization a model of muscie disuse? Exp. Neurol. 80: 147156

Garcia-Bunuel L., and V. M. Garcia-Bunuel (1980) Connective tissue metabolism in normal and atrophic skeletal muscle. J. Neurol. Sci. 47: 69-77.

Goldspink, D.F. (1977) The influence of immobilization and stretch on protein turnover in rat skeletal muscle. J. Physiol. (Lond.) 264: 267-282.

Goldspink, D. F. (1978) The influence of passive stretch on the growth and protein turnover of the denervated extensor digitorum longus muscle. Biochem. J. 774: 595-602

Gollnick, P. D., B. F. Timson, R. L. Moore, and M. Riedy (1981) Muscular enlargement and the number of fibers in the skeletal muscles of rats. $J$ Appl. Physiol. 50: 936-943.

Gutmann, E. (1976) Neurotrophic relations. Annu. Rev. Physiol. 38: $177-$ 216

Hatt, H., and D. O. Smith (1976) Synaptic depression related to presynaptic axon conduction block. J. Physiol. (Lond.) 259: 367-393.

Homsher, E., and J. A. Rall (1973) Energetics of shortening muscles in twitches and tetanic contractions. I. A reinvestigation of Hill's concept of shortening heat. J. Gen. Physiol. 62: 663-676.

Johrisur, D. J., L. A. Srith, E. Eldred, and V. R. Edgertor (1982) Exercise induced changes of biochemical, histochemical and contractile properties of muscle in cordotomized kittens. Exp. Neurol. 76: 414-427

Karpati, G., and W. K. Engel (1968) Correlative histochemical study of skeletal muscle after supraspinal denervation, peripheral nerve section, and skeletal fixation. Neurology 18: 681-692.

Kean, C. J. C., D. M. Lewis, and J. D. McGarrick (1974) Dynamic properties of fast and slow twitch muscle of the cat. J. Physiol. (Lond.) 237: 103113.

Krnjevic, K., and R. Miledi (1959) Presynaptic failure of neuromuscular propagation in rats. J. Physiol. (Lond.) 149:1-22

Kuno, M. (1964) Mechanism of facilitation and depression of the excitatory synaptic potential in spinal motoneurones. J. Physiol. (Lond.) 175: 100112.

Lavoie, P. -A., B. Collier, and A. Tennenhouse (1977) Role of skeletal muscle activity in the control of muscle acetylcholine sensitivity. Exp. Neurol. 54: 148171

Lewis, D. M. (1972) The effect of denervation on the mechanical and electrical properties of fast and slow mammalian twitch muscle. J. Physiol. (Lond.) 222. $51-75$

Maier, A., J. L. Crockett, D. R. Simpson, C. W. Saubert, Jr., and V. R. Edgerton (1976) Properties of immobilized guinea pig hindlimb muscles Am. J. Physiol. 231: 1520-1526.

McArdle, J. J. (1983) Molecular aspects of the trophic influence of nerve on muscle. Prog. Neurobiol. 21: 135-198.

McArdle, J. J., L. Michelson, and A. J. D'Alonzo (1980) Action potentials in fast- and slow-twitch skeletal mammalian muscles during re-innervation and development. J. Gen. Physiol. 75: 655-672

Musacchia, X. J., J. M. Steffen, and D. R. Deavers (1983) Rat hindlimb muscle responses to suspension hypokinesia/hypodynamia. Aviat. Space Environ. Med. 54: 1015-1020.

Ochs, S. (1982) Axoplasmic Transport and its Relation to Neurotrophic Functions, John Wiley \& Sons, Inc., New York.

Pestronk, A., D. B. Drachman, and J. W. Griffin (1976) Effect of muscle disuse on acetylcholine receptors. Nature 260: 352-353.

Peter, J. B., R. J. Barnard, V. R. Edgerton, C. A. Gillespie, and K. E. Stempel (1972) Metabolic profiles of three fiber types of skeletal muscle in guinea pigs and rabbits. Biochemistry 11: $2627-2633$

Redfern, P., and S. Thesleff (1971) Action potential generation in denervated rat skolctal musclc. 1. Quantitative aspccts. Acta Physiol. Scand. 81: 557 564.

Salmons, S., and F. A. Sreter (1976) Significance of impulse activity in the transformation of skeletal muscle type. Nature 263: 30-34

Saltin, B., and P. D. Gollnick (1983) Skeletal muscle adaptability: Significance for metabolism and performance. In Handbook of Physiology. Section 10: Skeletal Muscle, L. D., Peachy, ed., pp. 555-631, American Physiologica Society, Bethesda, MD.

Schilling, M. O. (1960) Capacitance transducers for muscle research. Rev Scient. Instrum. 31: 1215-1217.

Simard, C. P., S. A. Spector, and V. R. Edgerton (1982) Contractile properties of rat hind limb muscles immobilized at different lengths. Exp. Neurol. 77. $467-482$.

Smith, D. O. (1979) Reduced capabilities of synaptic transmission in aged rats. Exp. Neurol. 66: 650-666

Spector, S. A. (1985) Trophic effects on the contractile and histochemica properties of rat soleus muscle. J. Neurosci. 5: 2189-2196.

Spector, S. A, and V. R. Edgerton (1984) Deficits in neuromuscular transmission and contractile function in tetrodotoxin-disused rat skeletal muscle. Med. Sci. Sports Exerc. 16: 143.

Spector, S. A. C. P. Simard, M. Fournier, E. Sternlicht, and V. R. Edgerton (1982) Architectural alterations of rat hind limb skeletal muscle immobilized at different lengths. Exp. Neurol. 76: 94-110.

Thompson, W. (1983) Synapse elimination in neonatal rat muscle is sensitive to pattern of use. Nature 302: 614-616.

Tower, S. S. (1937) Trophic control of non-nervous tissues by the nervous system: A study of muscle and bone innervated from an isolated and quiescent region of spinal cord. J. Comp. Neurol. 67: 241-261.

Vrbova, G. (1963) The effect of motoneurone activity on the speed of contraction of striated muscle. J. Physiol. (Lond.) 169: 513-526. 